\title{
Synthesis of Symmetrical Acetophenone Azine Derivatives as Colorimetric and Fluorescent Cyanide Chemosensors
}

\author{
Nur Masyittah Irmi, Bambang Purwono*, and Chairil Anwar \\ Department of Chemistry, Faculty Mathematics and Natural Science, Universitas Gadjah Mada, \\ Sekip Utara, PO BOX BLS 21, Yogyakarta 55281, Indonesia
}

* Corresponding author:

email:purwono.bambang@ugm.ac.id

Received: March 1, 2021

Accepted: October 17, 2021

DOI: $10.22146 / \mathrm{ijc} .64428$

\begin{abstract}
Cyanide is a highly toxic anion and poison to the environment. Therefore, fast, effective, and efficient analysis methods to detect cyanide are needed. Herein, symmetrical chemosensor of 2'-hydroxy acetophenone azine (1) and 2',4'-dihydroxy acetophenone azine (2) has been synthesized tested as colorimetric and fluorescent cyanide chemosensor. The azines were produced from the condensation of acetophenone derivatives with hydrazine hydrate in ethanol under reflux or ultrasonic irradiation methods. Colorimetric and fluorescent chemosensor tests showed selectivity to acetate and cyanide anions in DMSO. The limit of detection (LOD) for colorimetric measurement of cyanide anion was $9.68 \times 10^{-4} \mathrm{M}$ for compound (1) and $9.63 \times 10^{-5} \mathrm{M}$ for compound (2), while the fluorescent method showed $15.90 \times 10^{-4} \mathrm{M}$ for compound (1) and $8.95 \times 10^{-5} \mathrm{M}$ for compound (2), respectively. In addition, test paper-strips containing sensor 2 indicated noticeable results for 'naked eye' detection of cyanide in an aqueous medium.
\end{abstract}

Keywords: acetophenone; azine; colorimetry; fluorescents; cyanide

\section{- INTRODUCTION}

Cyanide is a toxic anion that can affect the function of organ systems such as the vascular system, the sense of sight, central nervous system, heart, endocrine, and metabolic systems [1]. When cyanide ion enters the bloodstream, it disrupts the electron transport chain leading to cytotoxic hypoxia and death [2]. A small dose of cyanide ion around 0.5-3.5 $\mathrm{mg}$ of each $\mathrm{kg}$ body weight can cause death [3]. According to WHO, the cyanide detection limit in drinking waters is $0.07 \mathrm{mg}$ per liter or about $2.69 \times 10^{-6} \mathrm{M}[4]$.

Cyanide is widely used in industries such as gold mining, electroplating, metallurgy, and polymer productions. These industries produced 140,000 tons of waste per year [5]. Cyanide also occurs naturally as cyanogen glycosides in at least 2,000 types of plants, including apple, mango seeds, and several essential crops such as almonds, cassava, cherries, corn, cotton, and potatoes. Cyanide is also found in cigarette smoke, incomplete combustion of nitrogen-containing compounds from a vehicle, reaction of coke, coal, and limestone [6]. Therefore, detection of cyanide is essential. Some techniques such as chromatography [7], atomic absorption spectrometry [8], and electrochemical [9] have been used to detect cyanide anion. Nowadays, colorimetric and fluorescence chemosensors are attracting much attention because of low cost, high selectivity, simplicity, sensitivity, and fast recognition in real-time circumstances [10].

Some organic molecules containing amide, pyrrole, thiourea, and phenol groups can be used as cyanide chemosensors. Detections involve the formation of hydrogen bonding or deprotonation between cyanide and chemosensors. For example, Azine derivatives bearing hydroxyl group have been used as colorimetric and fluorescent chemosensors [1,5,11-13]. Most azine chemosensors were produced from aryl benzaldehydes and hydrazine hydrates as starting materials under reflux condition [14-16]. This paper reports the synthesis of symmetrical azine $\mathbf{1}$ and $\mathbf{2}$ from acetophenone derivatives and hydrazine hydrate (Scheme 1). The azines were then applied as colorimetric and fluorescent chemosensors for cyanide anion. 

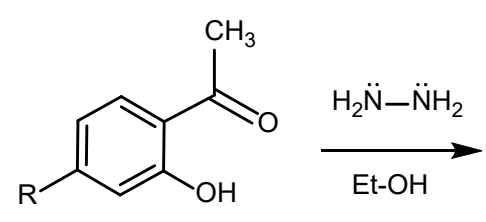<smiles>[R]c1ccc2c(c1)OCN=C2N1[CH]Oc2cc([R])ccc2C1C</smiles>

1. $^{\mathrm{R}=\mathrm{H}} \quad$ 2. $^{\mathrm{R}=\mathrm{OH}}$

Scheme 1. Synthesis targeted compounds 1 and 2

\section{- EXPERIMENTAL SECTION}

\section{Materials}

The materials used in this study were hydrazine hydrate $80 \%, 2$ '-hydroxy acetophenone, 2',4'-dihydroxy acetophenone, sodium fluoride, sodium chloride, sodium bromide, sodium iodide, sodium cyanide, sodium acetate, sodium hydroxide and hydrochloric acid 37\%, acetone, acetonitrile, dimethyl sulfoxide, ethanol, and distilled water. All chemicals used in this study were purchased from E. Merck with p.a. quality, while distilled water is obtained from the Organic Chemistry Laboratory of FMIPA-UGM.

\section{Instrumentation}

The equipment used in the experiment were laboratory glassware, hot plate, magnetic stirrer, thermometer $100{ }^{\circ} \mathrm{C}$, Buchner filter, analytical scales (Libror EB-330 Shimadzu), and ultrasonic irradiation (Ultrasonic Branson $43 \mathrm{KHz}, 43 \mathrm{Watts}$ ). The structure elucidation used FT-IR (Shimadzu Prestige-21), GC-MS (Shimadzu QP2010S), and ${ }^{1} \mathrm{H}-\mathrm{NMR}$ and ${ }^{13} \mathrm{C}-\mathrm{NMR}$ (JEOL JNM ECA-500, $500 \mathrm{MHz}$ ). The colorimetric study used UV-Vis Spectrophotometer (Shimadzu UV-1800), and the fluorescents study used Spectrofluorometer (Shimadzu RF-6000). The melting point was measured using uncorrected Electrothermal-9100.

\section{Procedure}

\section{Synthesis of acetophenone azine}

Acetophenone azines were synthesized based on the previous report with some modifications [16]. First, acetophenone derivative $(10 \mathrm{mmol})$ was dissolved in 10 $\mathrm{mL}$ of absolute ethanol, then $0.25 \mathrm{~mL}(5 \mathrm{mmol})$ of hydrazine hydrate (80\%) was added dropwise under stirring conditions. The solution was then heated under reflux for $2 \mathrm{~h}$ until a yellow precipitate formed. The stirring was continued at room temperature overnight.
The residue was filtered and washed with cold ethanol and then dried. The solid was then determined its melting point, and the structures were elucidated by FTIR, GC-MS, and ${ }^{1} \mathrm{H}$ - and ${ }^{13} \mathrm{C}-\mathrm{NMR}$. A similar procedure was also carried out through ultrasonic irradiation methods at room temperature for $1 \mathrm{~h}$.

Compound of 2'-hydroxy acetophenone azine (1) was obtained as a yellow solid in $73.13 \%$ yield for reflux method and $88.80 \%$ yield for ultrasonic irradiation methods (m.p. 197-198 ${ }^{\circ} \mathrm{C}$, literature 197-198 ${ }^{\circ} \mathrm{C}$ [17]). IR $\left(\mathrm{KBr} \mathrm{cm}^{-1}\right): 3448(\mathrm{O}-\mathrm{H}), 1604(\mathrm{C}=\mathrm{N}), 1496$ and 1442 ( $\mathrm{C}=\mathrm{C}$ aromatic), $1356\left(-\mathrm{CH}_{3}\right)$, and $840\left(\mathrm{Ar}-\mathrm{C}-\mathrm{CH}_{3}\right)$; ${ }^{1} \mathrm{H}-\mathrm{NMR}\left(\mathrm{CDCl}_{3}\right): \delta 2.56(\mathrm{~s}, 6 \mathrm{H}), 6.93$ (t.d, $J=8.4,1.3 \mathrm{~Hz}$, $2 \mathrm{H}$ ), 7.02 (d.d, $J=8.3,1.2 \mathrm{~Hz}, 2 \mathrm{H}$ ), 7.36 (t.d, $J=8.6,1.6 \mathrm{~Hz}$, $2 \mathrm{H}), 7.63$ (d.d, $J=8.1,1.6 \mathrm{~Hz}$ ), and 13.26 (s, 2H); ${ }^{13} \mathrm{C}-\mathrm{NMR}$ $\left(\mathrm{CDCl}_{3}\right): \delta 14.96,118.01,119.09,119.14,129.06,133.00$, 160.69, and 168.19. Mass spectra (m/z): $268\left(\mathrm{M}^{+}\right)$.

Compound of 2',4'-dihydroxy acetophenone azine (2) was obtained as a pale-yellow solid in $68 \%$ yields from reflux method, and $82.67 \%$ yields from ultrasonic irradiation methods (m.p. 271-272 ${ }^{\circ} \mathrm{C}$, literature 269270 [18]). IR ( $\left.\mathrm{KBr} \mathrm{cm}^{-1}\right): 3417(\mathrm{O}-\mathrm{H}), 1604(\mathrm{C}=\mathrm{N}), 1504$ and $1442\left(\mathrm{C}=\mathrm{C}\right.$ aromatic), $1357\left(-\mathrm{CH}_{3}\right)$, and 833 ( $\mathrm{Ar}-$ C-CH $\mathrm{CH}_{3}$ ); ${ }^{1} \mathrm{H}-\mathrm{NMR}$ (DMSO): $\delta 2.41(\mathrm{~s}, 6 \mathrm{H}), 6.27$ (d, $J=$ $2.5 \mathrm{~Hz}, 2 \mathrm{H}), 6.35$ (d.d, $J=8.8,2.5 \mathrm{~Hz}, 2 \mathrm{H}), 7.56$ (d, $J=$ $8.9,2 \mathrm{H}), 10.12(\mathrm{~s}, 2 \mathrm{H})$, and $13.55(\mathrm{~s}, 2 \mathrm{H}) ;{ }^{13} \mathrm{C}-\mathrm{NMR}$ (DMSO): $\delta 14.48,103.42,108.15,111.84,131.69,162.16$, 162.63, and 167.54. Mass spectra $(\mathrm{m} / \mathrm{z}): 300\left(\mathrm{M}^{+}\right)$.

\section{Solvatochromic effect on sensor compounds}

Compounds $\mathbf{1}$ and $\mathbf{2}$ were dissolved in acetone, acetonitrile, DMSO, and ethanol, respectively, in a concentration of $10^{-3} \mathrm{M}$. Color of the solutions was observed and then measured with a UV-Vis spectrophotometer at a concentration of $5 \times 10^{-5} \mathrm{M}$ for $\mathbf{1}$ and $2 \times 10^{-5} \mathrm{M}$ for 2 . 


\section{Acid-base effect on sensor compounds}

Color changes of solution (1 and 2) were observed after dropping $1 \mathrm{~mL}$ of $\mathrm{HCl}$ or $\mathrm{NaOH} 10 \%$ (w/v) into each sensor solution $\left(5 \times 10^{-5} \mathrm{M}\right.$ for 1 and $2 \times 10^{-5} \mathrm{M}$ for 2$)$ in DMSO for a total volume of $10 \mathrm{~mL}$. The color of the solution was observed and then measured with a UV-Vis spectrophotometer. Distilled water $(1 \mathrm{~mL})$ was used as a reference solution.

\section{lonic effect on sensor compounds}

Sodium salt solutions of $\mathrm{NaF}, \mathrm{NaCl}, \mathrm{NaBr}, \mathrm{NaI}$, $\mathrm{NaCN}$, and $\mathrm{CH}_{3} \mathrm{COONa}$ were prepared with a concentration of $1 \mathrm{M}$ in distilled water. The $1 \mathrm{~mL}$ of sodium salt solution was added into solution $1\left(5 \times 10^{-5} \mathrm{M}\right)$ and solution $2\left(2 \times 10^{-5} \mathrm{M}\right)$ to a total volume of $10 \mathrm{~mL}$. The color of the solution was observed and then measured with a UV-Vis spectrophotometer and spectrofluorometer.

\section{Limit of detection for cyanide anion}

The limit of detection was carried out by adding $1 \mathrm{~mL}$ of various concentrations of $\mathrm{NaCN}\left(10^{-4}-10^{-1} \mathrm{M}\right)$ into solution $1\left(5 \times 10^{-5} \mathrm{M}\right)$ and $2\left(2 \times 10^{-5} \mathrm{M}\right)$ to a total volume of $10 \mathrm{~mL}$. The spectra were measured using a UVVis spectrophotometer and spectrofluorometer. Then, a calibration curve was plotted cyanide concentration vs. absorbance correlation. The limit of detection (LOD) values were determined by the $3 \sigma / \mathrm{m}$ equation, where $\sigma$ is the standard deviation and $\mathrm{m}$ is the slope of the calibration curve [19].

\section{Interaction study between sensor compounds and cyanide}

The interaction between sensor compounds and cyanide anion was determined by measuring Job's plot curve [20]. The concentration of sensor solution was $5 \times 10^{-5} \mathrm{M}$ for compound $\mathbf{1}$ and $2 \times 10^{-5} \mathrm{M}$ for compound 2 in DMSO, and a standard solution of $\mathrm{NaCN} 1 \mathrm{M}$ was used to make a fraction of 0.1-0.9 into sensor solutions. Then the absorbance was measured using a UV-Vis spectrophotometer. The curve was plotted as the mole fraction of cyanide vs. the absorbance. Finally, the ${ }^{1} \mathrm{H}$ NMR titration was conducted from a mixture of $\mathbf{2}$ and cyanide solutions in DMSO-d6.

\section{Paper-strip sensor}

Paper-strip sensor was carried out by immobilizing compounds $\mathbf{1}$ and $\mathbf{2}\left(1 \times 10^{-3} \mathrm{M}\right.$ in DMSO $)$ to filter paper (Whatman no. $42-1 \times 3 \mathrm{~cm}$ ) for $2 \mathrm{~h}$ and then dried using an oven. The test was conducted by dropping 2-3 drops of cyanide anion solution to the paper-strip sensor. The color change of paper-strip was observed directly and under a $365 \mathrm{~nm}$ UV lamp. As a negative control, distilled water was dropped on a paper-strip sensor.

\section{- RESULTS AND DISCUSSION}

\section{Solvatochromic Effect on Compounds 1 and $\mathbf{2}$}

The solvatochromic test was carried out by dissolving compounds $\mathbf{1}$ and $\mathbf{2}$ in several solvents of acetone, acetonitrile, ethanol, and DMSO. The optical color change and UV-Vis spectra are shown in Fig. 1.

The different colors of sensor solution in various solvents were observed. Compound $\mathbf{1}$ showed colorlessness, while compound $\mathbf{2}$ showed a brighter yellow color in ethanol and DMSO (Fig. 1(a, b)). From UV-Vis spectra (Fig. 1(c)), compound 1 gave two absorption peaks at $\lambda_{\max }$ of 294, 290, 296, and $292 \mathrm{~nm}$ and the second peak at $\lambda_{\max }$ of $362,354,360$, and $360 \mathrm{~nm}$ for acetone, acetonitrile, DMSO, and ethanol solvent respectively. Thus, the absorption peak of compound $\mathbf{1}$ solutions was at adjacent $\lambda_{\max }$. These data indicated that the effect of solvent polarity is small for the color changes. From Fig. 1(d), compound 2 exhibits one $\lambda_{\max }$ at $378 \mathrm{~nm}$ in DMSO. Two absorption peaks were observed from acetone, acetonitrile, and ethanol solvents, respectively. One low peak was around $\lambda_{\max }$ at $300 \mathrm{~nm}$ and a peak at $\lambda_{\max }$ at $370,368,374 \mathrm{~nm}$ for acetone, acetonitrile, and ethanol solvent, respectively. These data also indicated that the effect of solvent polarity is small for the color changes. However, compound 2 in DMSO and ethanol still provided shoulder absorption at $\lambda_{\max }$ of the visible area.

\section{Effect of Acid-Base Addition on Sensor Compounds}

Strong acid and base addition were applied into sensor solutions by adding $\mathrm{HCl} 10 \%$ or $\mathrm{NaOH} 10 \%$. As shown in Fig. 2, the color of solutions $\mathbf{1}$ and $\mathbf{2}$ was unchanged after adding $\mathrm{HCl} 10 \%$. However, the addition of $\mathrm{NaOH} 10 \%$ caused the color change from colorless to a very light yellow for compound $\mathbf{1}$ and yellow for compound 2 . 
(a)

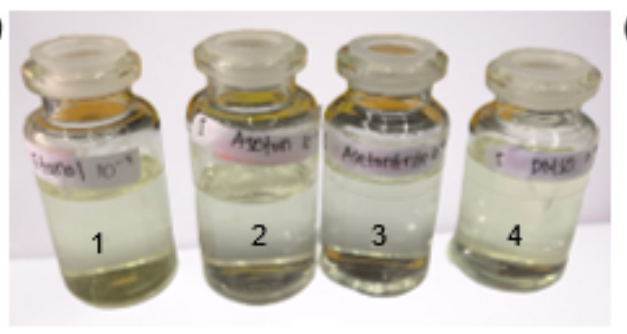

(b)

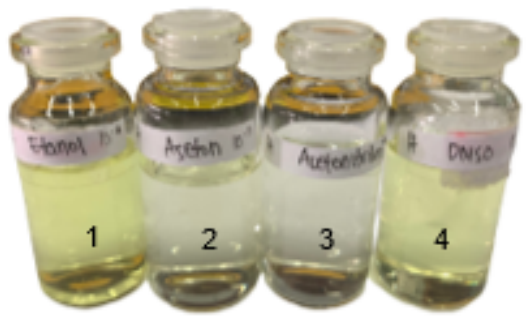

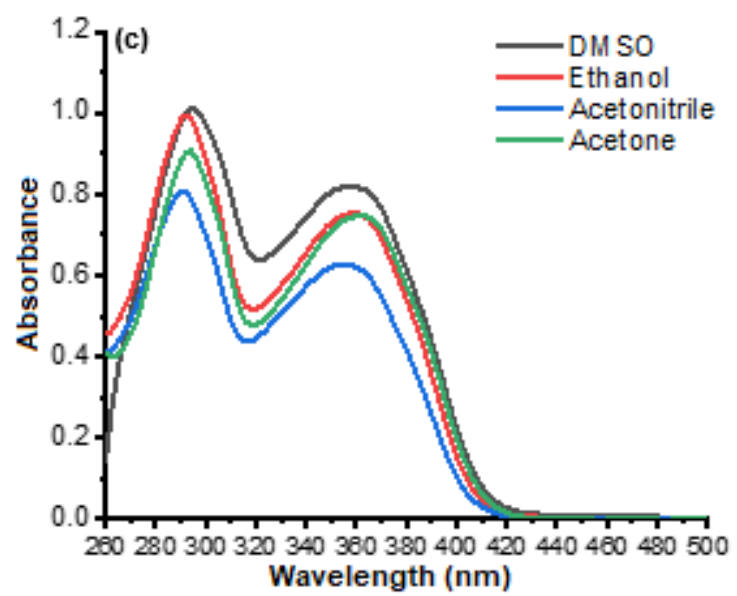

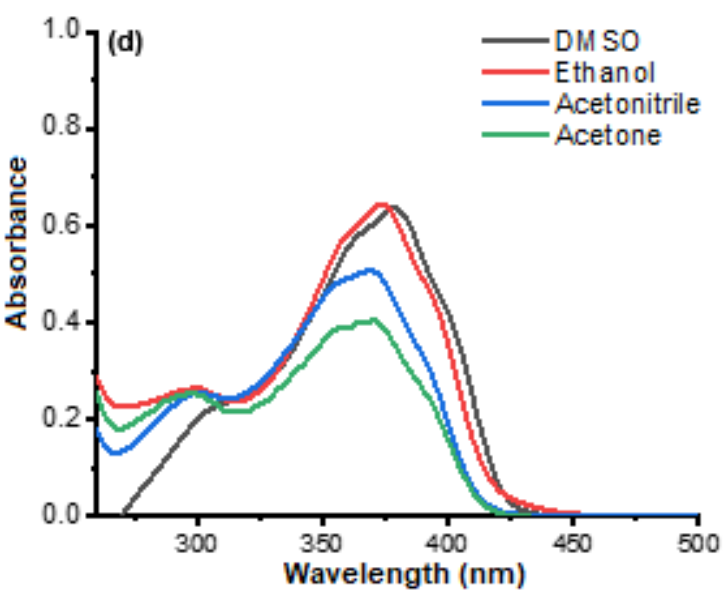

Fig 1. Optical color of (a) compound 1 and (b) 2 with a concentration of $10^{-3} \mathrm{M}$ changes in (1) ethanol, (2) acetone, (3) acetonitrile, and (4) DMSO and UV-Vis absorption spectra of (c) compound $1\left(5 \times 10^{-5} \mathrm{M}\right)$ and (d) $2\left(2 \times 10^{-5} \mathrm{M}\right)$ in various solvents

The yellow color was obtained because the addition of bases can deprotonate the $\mathrm{pH}$-sensitive groups [21]. Deprotonation of the $\mathrm{H}$ atom on hydroxyl group of compound 2 produced phenoxide ion and followed delocalization of electrons. Compound 2 has a more probable resonance structure than compound 1. More resonance structures will create a distinct color change in the solution [22]. Therefore, compound 2 has stronger yellow color than compound $\mathbf{1}$. The light-yellow color of compound $\mathbf{1}$ is produced from compound $\mathbf{1}$ with cyanide anion via hydrogen bonding formation, not deprotonation.

The color change of compounds $\mathbf{1}$ and $\mathbf{2}$ on the acidbase addition supported UV-vis spectra shown in Fig. 3. The addition of $\mathrm{HCl}$ to compound $\mathbf{1}$ causes a shift of two absorption peaks at $\lambda_{\max }$ of 296 and $360 \mathrm{~nm}$ into a peak at $\lambda_{\max }$ of $324 \mathrm{~nm}$. The addition of $\mathrm{NaOH}$ produced a shift of $\lambda_{\max }$ from 296 and $360 \mathrm{~nm}$ to 266 and $354 \mathrm{~nm}$. Both additions of acid and base did not create a bathochromic shift, so no color change was observed.

For compound 2, the addition of $\mathrm{HCl}$ causes a shift

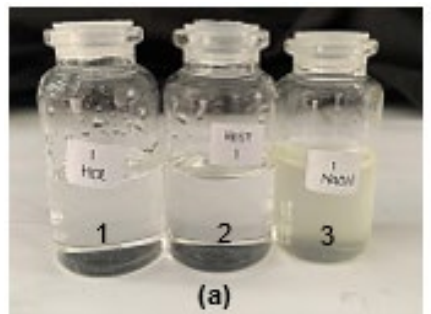

Fig 2. The color of solutions (a) compound $1\left(5 \times 10^{-5} \mathrm{M}\right)$ and (b) compound $2\left(2 \times 10^{-5} \mathrm{M}\right)$ in DMSO changes after addition (1) $\mathrm{HCl} 10 \%$, (2) $\mathrm{H}_{2} \mathrm{O}$, and (3) $\mathrm{NaOH} 10 \%$

of $\lambda_{\max }$ of $378 \mathrm{~nm}$ to two absorption peaks at $\lambda_{\max }$ of 280 and $316 \mathrm{~nm}$. The addition of $\mathrm{NaOH}$ produced a change of $\lambda_{\max }$ on $378 \mathrm{~nm}$ to $272 \mathrm{~nm}$ and appearance shoulder peak at $\lambda_{\max }>400 \mathrm{~nm}$. The shoulder peak at $\lambda_{\max }$ $>400 \mathrm{~nm}$ supported a yellow color formation after the addition of $\mathrm{NaOH}$.

\section{Ionic Effect on Sensor Compounds}

The ionic effect was carried out by anion addition into sensor solutions. The color change after addition $1 \mathrm{~mL}$ of $1 \mathrm{M}$ sodium salt from $\mathrm{NaF}, \mathrm{NaCl}, \mathrm{NaBr}, \mathrm{NaI}$, 

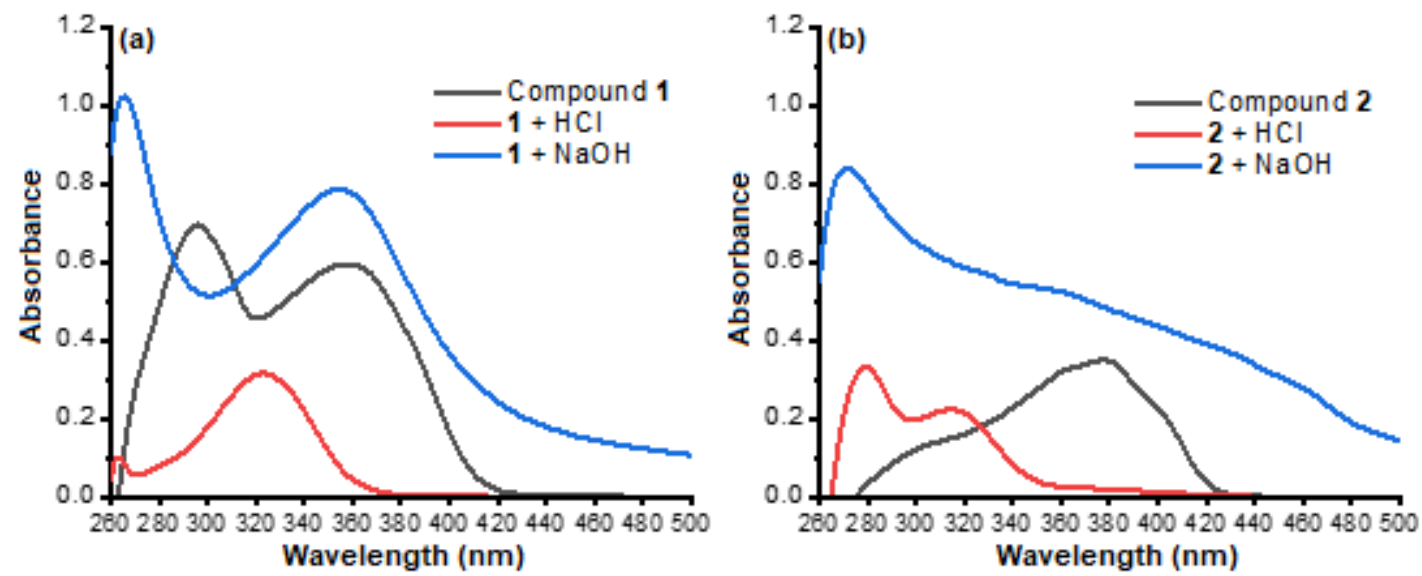

Fig 3. UV-Vis absorption spectra of (a) compound $1\left(5 \times 10^{-5} \mathrm{M}\right)$ and (b) compound $2\left(2 \times 10^{-5} \mathrm{M}\right)$ in DMSO after addition of $\mathrm{HCl} 10 \%$ and $\mathrm{NaOH} 10 \%$

$\mathrm{NaCN}, \mathrm{NaOAc}$, and a mixture of all salts is shown in Fig. 4. Adding $\mathrm{Cl}^{-}, \mathrm{Br}^{-}$and $\mathrm{I}^{-}$anion into compounds $\mathbf{1}$ and $\mathbf{2}$ did not produce a color change. The color change to yellow and cloudy was observed after addition $\mathrm{F}^{-}$into compound 2, while compound $\mathbf{1}$ was only cloudy with no color change. A significant color change was observed when $\mathrm{CN}^{-}$anion was added to a solution of compounds $\mathbf{1}$ and 2. The addition of $\mathrm{AcO}^{-}$gave a significant intense yellow color change for compound 2 . The addition of a mixture of all anions into compounds $\mathbf{1}$ and $\mathbf{2}$ caused the color change to a slightly yellowish color for compound $\mathbf{1}$ and a significant yellow color change for compound $\mathbf{2}$. These color changes indicated that there is no anion interference from those anions.
The color changes after the addition of anions were supported by the UV-Vis spectra shown in Fig. 5. The addition of $\mathrm{Cl}^{-}, \mathrm{Br}^{-}, \mathrm{I}^{-}, \mathrm{AcO}^{-}$to $\mathbf{1}$ did not give new absorption peaks in the visible light region. $\mathrm{CN}^{-}$and the mixture of all anions increased absorbance at $\lambda$ 420-440 $\mathrm{nm}$. The addition of $\mathrm{Cl}^{-}, \mathrm{Br}^{-}$and $\mathrm{I}^{-}$into the solution of $\mathbf{2}$ did not produce a change in $\lambda_{\max }$. The $\lambda_{\max }$ shift toward visible light (about $430 \mathrm{~nm}$ ) occurred when $\mathrm{AcO}^{-}, \mathrm{CN}^{-}$ and the mixture of all anions was added into a solution of 2.

The addition of $\mathrm{F}^{-}$into compounds $\mathbf{1}$ and $\mathbf{2}$ caused the color of solutions to become cloudy, making good UV-VIS spectra impossible. The formation of cloudiness is due to a strong hydrogen bond formed

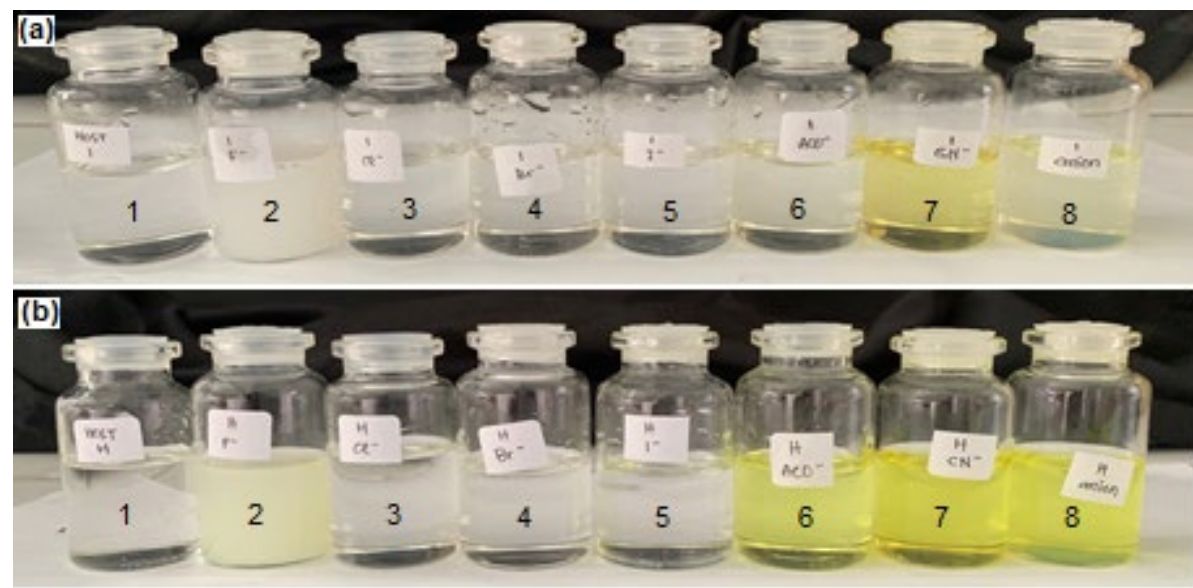

Fig 4. Color of solutions (a) compound $1\left(5 \times 10^{-5} \mathrm{M}\right)$ and (b) compound $2\left(2 \times 10^{-5} \mathrm{M}\right)$ in DMSO changes after addition (1) $\mathrm{H}_{2} \mathrm{O}$, 2) $\mathrm{F}^{-}$, (3) $\mathrm{Cl}^{-}$, (4) $\mathrm{Br}^{-}$, (5) $\mathrm{I}^{-}$, (6) $\mathrm{AcO}^{-}$, (7) $\mathrm{CN}^{-}$, and (8) mixture of all anions 

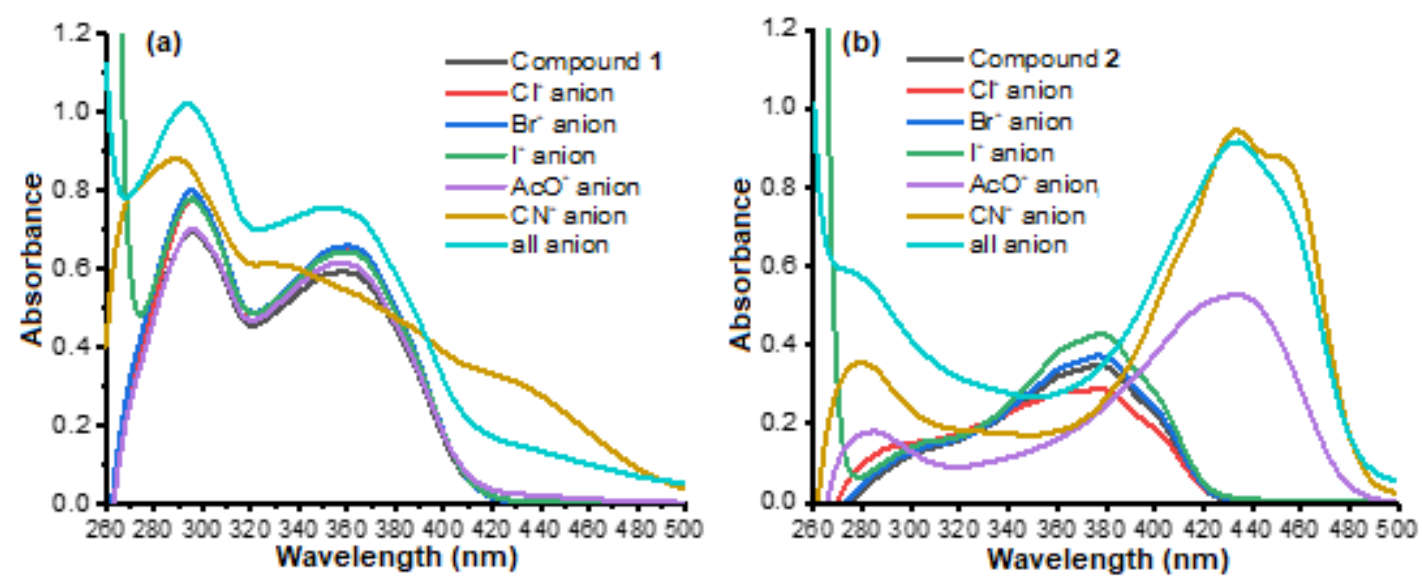

Fig 5. UV-Vis absorption spectra of (a) compound $1\left(5 \times 10^{-5} \mathrm{M}\right)$ and (b) compound $2\left(2 \times 10^{-5} \mathrm{M}\right)$ in DMSO after addition of anions

between $\mathrm{F}^{-}$and water and may decrease anion solubility in DMSO.

Fluorescence properties were observed with a $365 \mathrm{~nm}$ UV light (Fig. 6). Both compounds 1 and 2 did not exhibit fluorescence. The addition of all tested anions showed the fluorescence intensities of compound $\mathbf{1}$, while compound 2 did not give fluorescence with the addition of iodide ion only (Fig.6(a, b)).
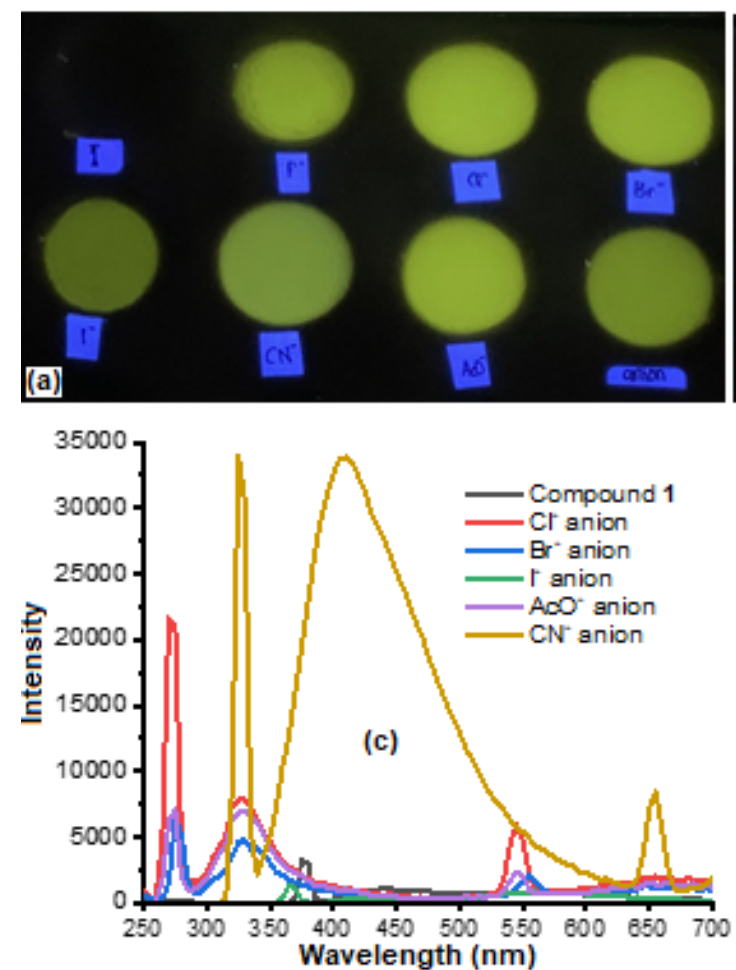

The fluorescents changes were supported by emission spectra shown in Fig. 6(c) and d. In addition, $\mathrm{CN}^{-}$anion gives a high-intensity emission for both compounds 1 and 2. Excitation of compound 1 occurs at $\lambda 335 \mathrm{~nm}$ with the highest emissions at $\lambda_{\max }$ around $400-$ $450 \mathrm{~nm}$, while compound 2 excites at $\lambda_{\max } 415 \mathrm{~nm}$ with the highest emission at $500-530 \mathrm{~nm}$. The increasing fluorescents intensity of sensor solutions after addition
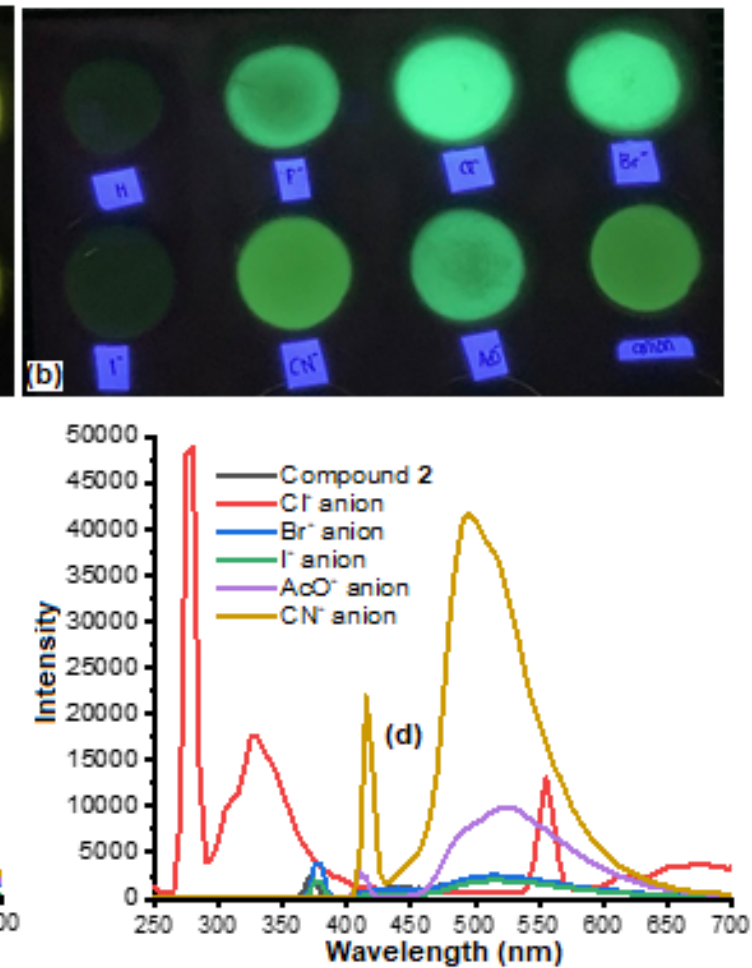

Fig 6. Fluorescents of solution (a) compound $\mathbf{1}\left(5 \times 10^{-5} \mathrm{M}\right)$ and (b) compound $2\left(2 \times 10^{-5} \mathrm{M}\right)$ under a UV lamp $365 \mathrm{~nm}$; and emission spectra of (c) compound 1 and (d) compound 2 in DMSO after addition of $\mathrm{Cl}^{-}, \mathrm{Br}^{-}, \mathrm{I}^{-}, \mathrm{AcO}^{-}$, and $\mathrm{CN}^{-}$ 
of $\mathrm{CN}^{-}$indicates an OFF-ON system due to interaction between sensor compound and anion [23].

\section{Limit of Detection Value for Cyanide on Sensor Compounds}

The color changes of sensor solutions after addition various $\mathrm{CN}^{-}$concentrations are shown in Fig. 7. The solution color change into yellow was observed when the $\mathrm{CN}^{-}$concentrations were $4 \times 10^{-2} \mathrm{M}$ for 1 and $1 \times 10^{-3} \mathrm{M}$ for 2.

The UV-Vis spectra after the addition of various cyanide anion concentrations are shown in Fig. 8. For example, the addition of cyanide from a range concentration of $10^{-4}-10^{-2} \mathrm{M}$ into compound $\mathbf{1}$ caused a decrease in absorbance at $\lambda \sim 290$ and $360 \mathrm{~nm}$ and increased a new peak at $\lambda \sim 450 \mathrm{~nm}$ region (Fig. 8(a)). For compound 2, increasing $\mathrm{CN}^{-}$concentration from $10^{-5}$ $10^{-3} \mathrm{M}$ caused a decrease in absorbance at $\lambda_{\max } 380 \mathrm{~nm}$ and a new peak at $\lambda \sim 440 \mathrm{~nm}$ (Fig. 8(b)).

A ratiometric calibration curve was plotted from
UV-Vis spectra to determine the limit of detection (LOD) cyanide anion of compounds 1 and 2. The ratiometric calibration curve against various $\mathrm{CN}^{-}$ concentrations had a regression value $\left(\mathrm{R}^{2}\right)$ of 0.9916 with a LOD value of $9.6 \times 10^{-4} \mathrm{M}$ for compound 1 and 0.9917 with a LOD value of $9.63 \times 10^{-5} \mathrm{M}$ for compound 2 .

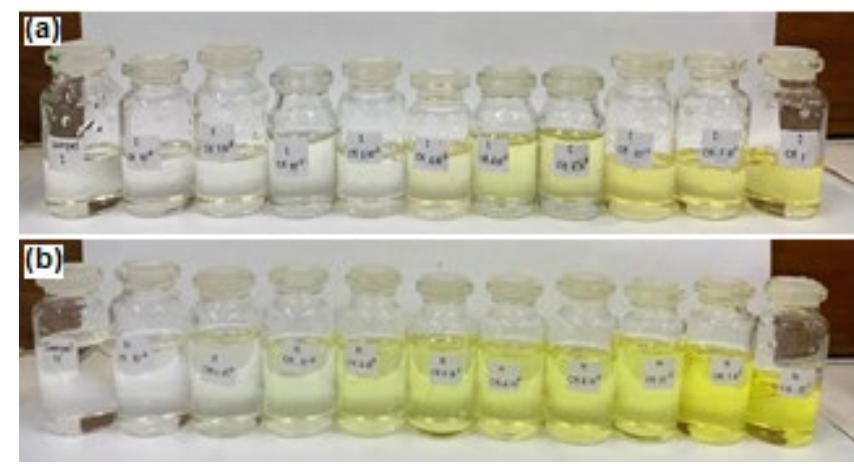

Fig 7. Optical color of (a) compound 1 and (b) compound $\mathbf{2}$ changes after addition of various concentrations of cyanide anion $\left(10^{-4}-10^{-2} \mathrm{M}\right.$ for compound 1 and $10^{-5}-10^{-2} \mathrm{M}$ for compound 2)
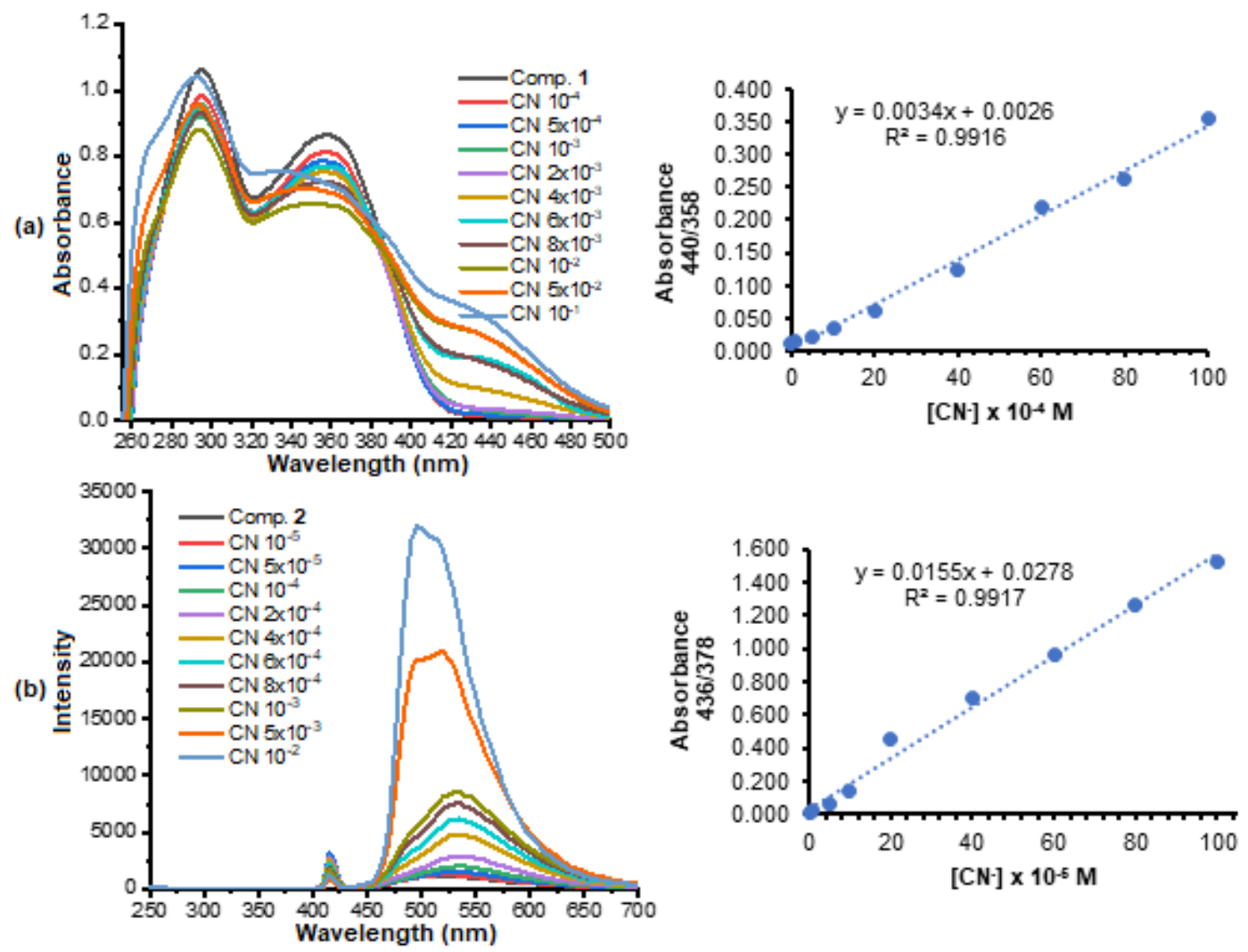

Fig 8. UV-Vis absorption spectra with the ratiometric curve of (a) compound $\mathbf{1}$ and (b) compound $\mathbf{2}$ after addition various concentrations of $\mathrm{CN}^{-}$ 
The LOD value for $\mathrm{CN}^{-}$anion was also performed using a spectrofluorometer. The fluorescence emission spectra and calibration curve are shown in Fig. 9. The emission spectra of compounds $\mathbf{1}$ and $\mathbf{2}$ increased with an increase of $\mathrm{CN}^{-}$concentration. As a result, the calibration curve of the emission spectra of compounds $\mathbf{1}$ and $\mathbf{2}$ had an $\mathrm{R}^{2}$ value of 0.9776 and 0.9928 , and the LOD value was $15.90 \times 10^{-4} \mathrm{M}$ and $8.95 \times 10^{-5} \mathrm{M}$.

\section{Interaction Study between Sensor Compounds and Cyanide}

The interaction study between sensor compounds and cyanide anions was performed through Job's plot [20]. The curves of absorbances against the cyanide fraction are shown in Fig. 10. The maximum absorbance was obtained at addition a cyanide fraction of 0.5 . This value indicates that interaction between compounds $\mathbf{1}$ and $\mathbf{2}$ with the cyanide anion has a mole ratio of 1:1. The 1:1 ratio means that only one hydroxyl from the symmetrical azine interacts with one mole of cyanide anion.
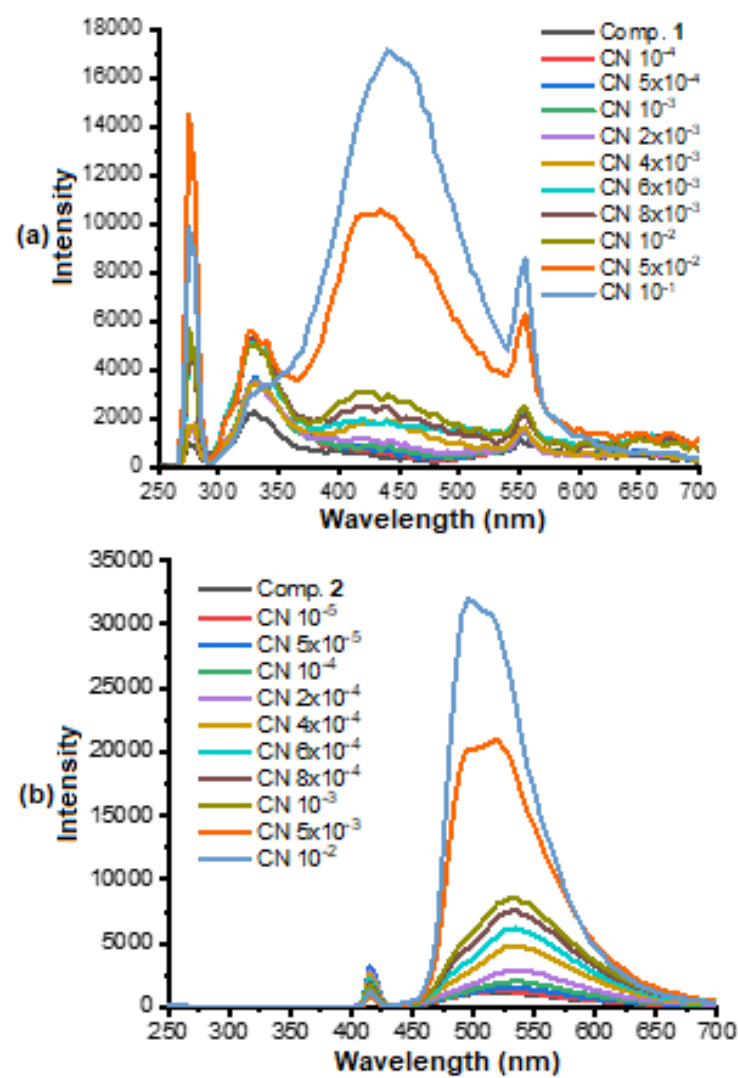

Fig 9. Emission spectra with the calibration curve of (a) compound 1 and (b) compound 2 at the excitation of $415 \mathrm{~nm}$ after addition various concentrations of $\mathrm{CN}^{-}$
The ${ }^{1} \mathrm{H}-\mathrm{NMR}$ titration supported 1:1 ratio interaction for compound 2 (Fig. 11). The addition of 1
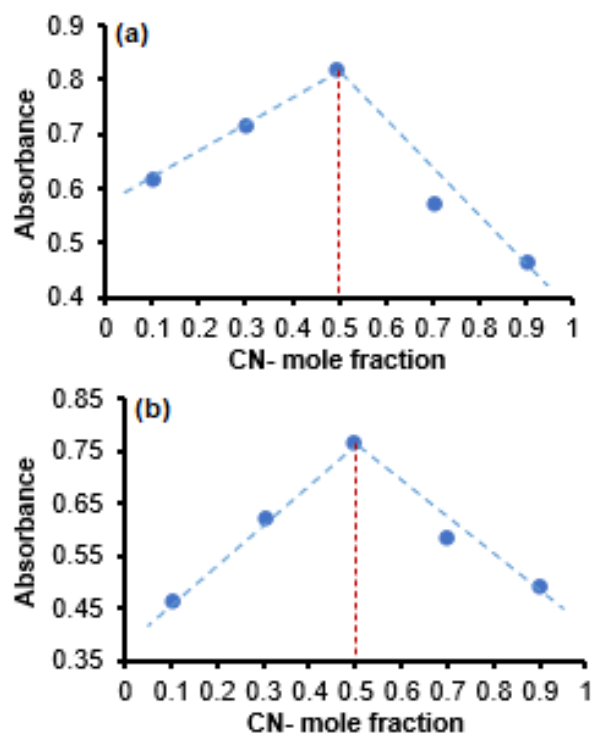

Fig 10. Job's Plot curve interaction between (a) compound 1 and (b) compound 2 with a fraction of cyanide addition
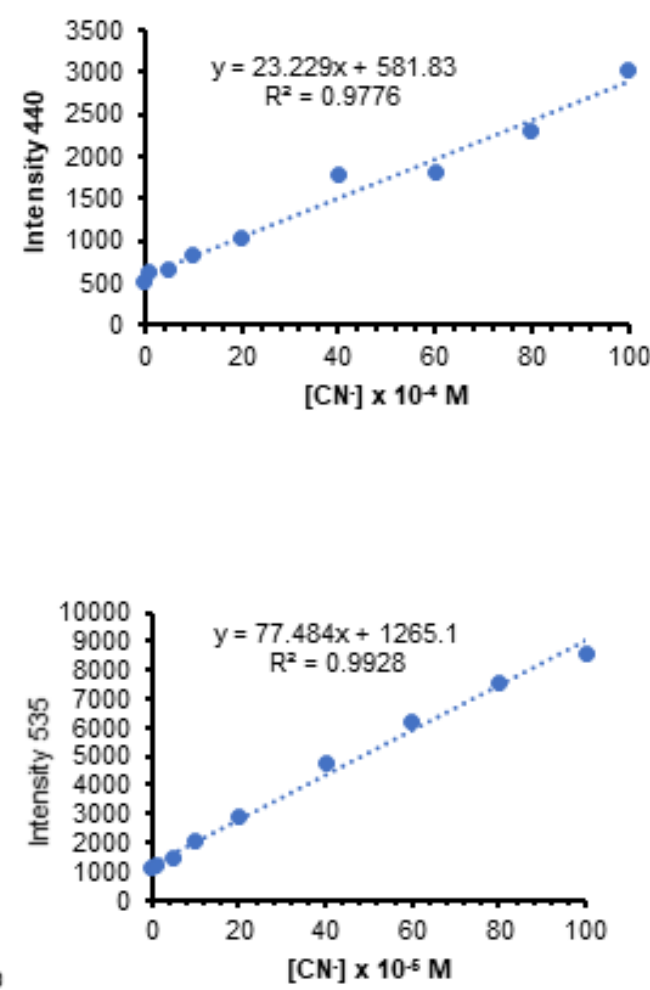
equivalent mole ratio of cyanide anion caused a signal at $13.55 \mathrm{ppm}$ to disappear and followed a new signal at 8.51 ppm. The addition of 5 and 10 moles equivalents of cyanide anion, a signal at $\delta 8.51 \mathrm{ppm}$ shifted towards upfield at 8.48 and $8.44 \mathrm{ppm}$ accompanied by an increase in the absorption intensity. The proton of benzene peaks gradually showed a shift to the upfield area. This data indicated that deprotonation of the hydroxyl group has occurred in one hydroxyl group. These results are proposed to the mechanism of interactions in Scheme 2.

The proposed mechanism supported color change after the addition of cyanide. Interaction of compound $\mathbf{1}$ with cyanide indicated the formation of $\mathrm{H}$-bond with cyanide anion in one hydroxyl group. This interaction did not produce delocalization of the benzene ring, so the color change was not intense. Interaction of compound 2 with cyanide indicated the deprotonation of one hydroxyl group followed with delocalization of the phenol anion producing color change.

\section{Paper-Strip Sensor}

A paper-strip sensor was done by dropping various concentrations of cyanide anion solution (0-1 M) to a Whatman filter immobilized with compounds $\mathbf{1}$ and 2.

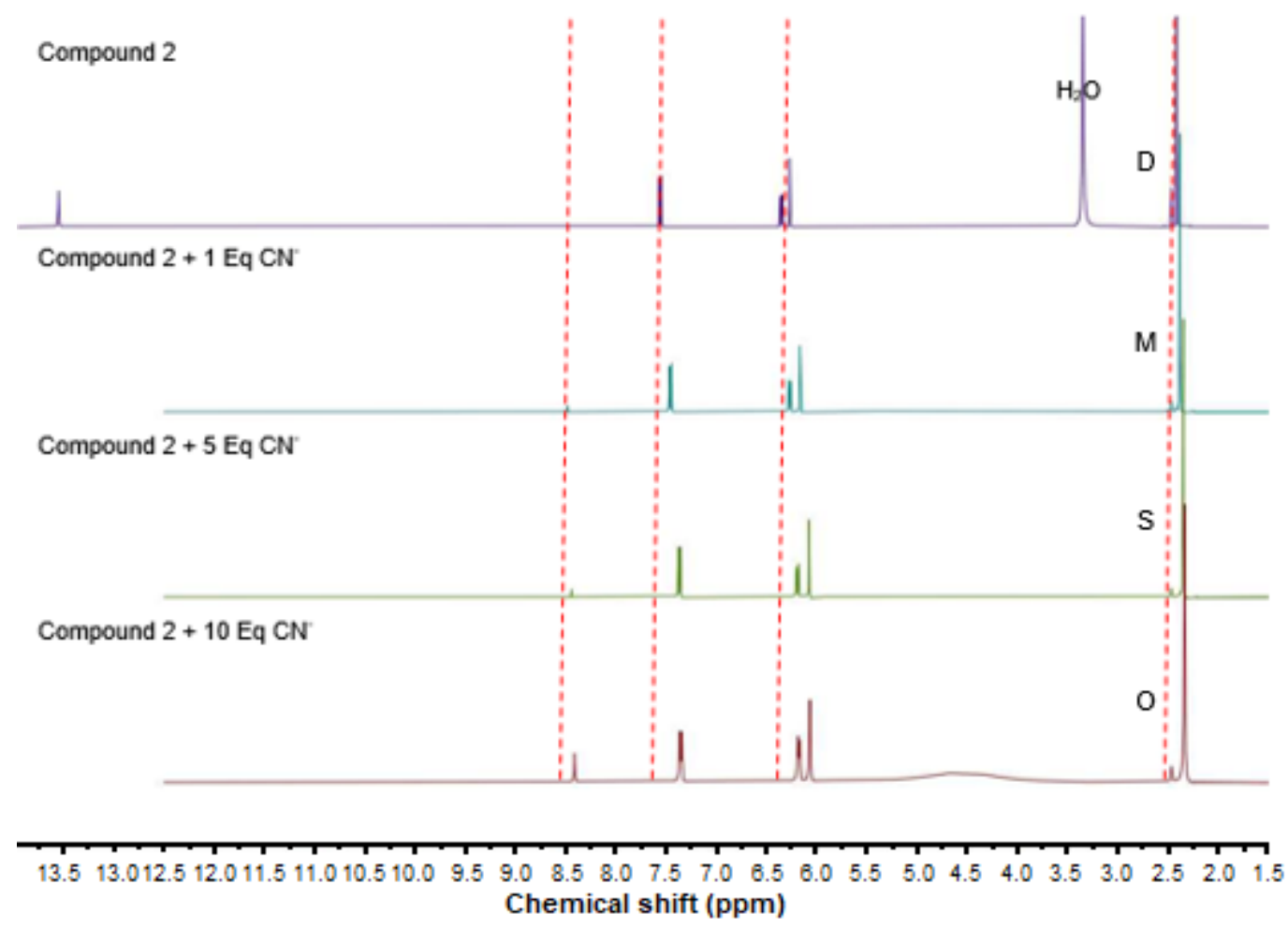

Fig 11. ${ }^{1} \mathrm{H}-\mathrm{NMR}$ titration on compound 2 with the addition of cyanide ion
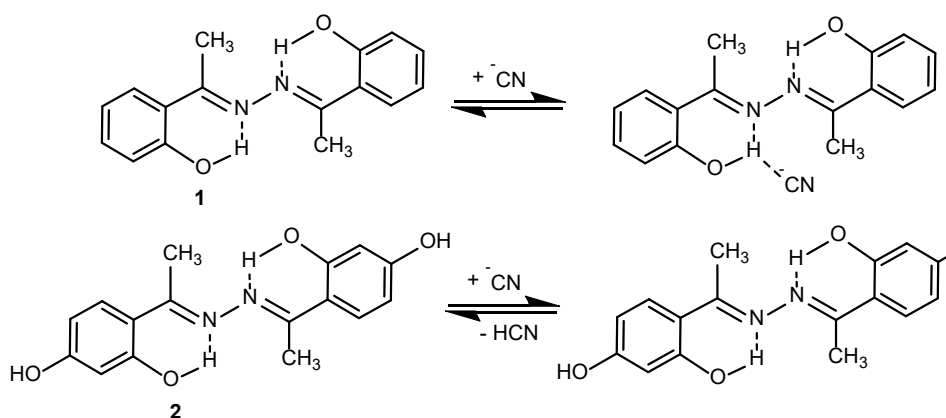<smiles>CC1=NCOc2cc(O)ccc21</smiles>

Scheme 2. Proposed mechanism of interaction $\mathbf{1}$ and $\mathbf{2}$ with cyanide anion 


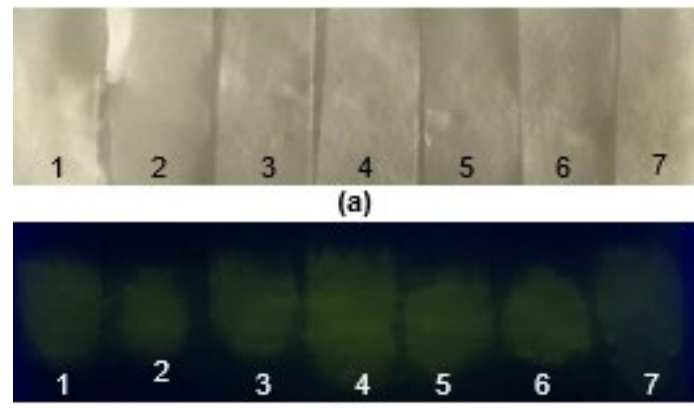

(c)

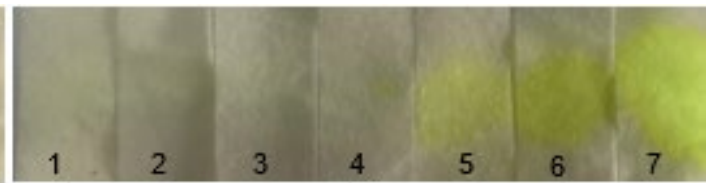

(b)

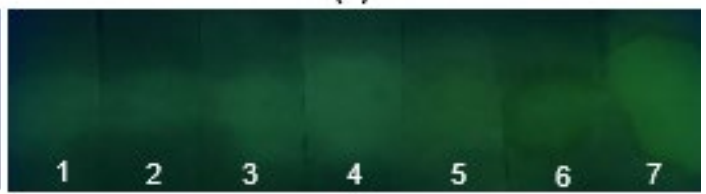

(d)

Fig 12. The paper-strip color of (a) sensor 1 and (b) sensor 2 changes after addition of various $\mathrm{CN}^{-}$concentration (1) $0 \mathrm{M}$; (2) $10^{-5} \mathrm{M}$; (3) $10^{-4} \mathrm{M}$; (4) $10^{-3} \mathrm{M}$; (5) $10^{-2} \mathrm{M}$; (6) $10^{-1} \mathrm{M}$; and (7) $1 \mathrm{M}$, (c) sensor 1 and (d) sensor 2 under a 365 nm UV lamp

The results are shown in Fig. 12. The paper-strip sensor $\mathbf{1}$ produced no 'naked-eye' color change in addition to various cyanide anion concentrations. In contrast, paperstrip sensor 2 could detect the presence of cyanide anions at a concentration of 10-2 $\mathrm{M}$ with a concentration of a pale-yellow color. Observing the paper-strips under a $365 \mathrm{~nm}$ UV lamp, paper-strip sensors 1 and 2 glow when the cyanide is dripped with distilled water. Paper-strip $\mathbf{1}$ brought out a yellow glow, while paper-strip 2 gave a greenish-yellow glow. However, based on these results, it can be said that compound $\mathbf{1}$ and $\mathbf{2}$ is not sensitive to detect cyanide anions under UV light irradiation at a 365 nm UV lamp.

\section{- CONCLUSION}

Acetophenone azine derivatives $\mathbf{1}$ and $\mathbf{2}$ have been synthesized in one-step condensation of acetophenone derivatives with hydrazine hydrate. Compounds $\mathbf{1}$ and $\mathbf{2}$ can act as dual-mode chemosensors (colorimetry and fluorometry) to detect cyanide anion. Compound $\mathbf{2}$ has more sensitivity than compound 1. The LOD values for cyanide anion by colorimetry was $9.68 \times 10^{-4} \mathrm{M}$ for compound 1 and $9.63 \times 10^{-5} \mathrm{M}$ for compound 2, while LOD values by fluorescent were $15.90 \times 10^{-4} \mathrm{M}$ for compound 1 and $8.95 \times 10^{-5} \mathrm{M}$ for compound 2 .

\section{- ACKNOWLEDGMENTS}

We gratefully acknowledge to Indonesian Government through the LPDP scholarship to Nur Masyittah Irmi.

\section{- REFERENCES}

[1] Pei, P.X., Hu, J.H., Chen, Y., Sun, Y., and Qi, J., 2017, A novel dual-channel chemosensor for $\mathrm{CN}^{-}$ using asymmetric double-azine derivatives in aqueous media and its application in bitter almond, Spectrochim. Acta, Part A, 181, 131-136.

[2] Jia, X., Yang, Y., He, Y., Ma, Q., and Liu, Y., 2019, Theoretical study on the sensing mechanism of a fluorescence chemosensor for the cyanide anion, Spectrochim. Acta, Part A, 216, 258-264.

[3] Erdemir, S., and Malkondu, S., 2020, On-site and low-cost detection of cyanide by simple colorimetric and fluorogenic sensors: Smartphone and test strip applications, Talanta, 207, 120278.

[4] Ferreira, N.L., de Cordova, L.M., Schramm, A.D.S., Nicoleti, C.R., and Machado, V.G., 2019, Chromogenic and fluorogenic chemodosimeter derived from Meldrum's acid detects cyanide and sulfide in aqueous medium, J. Mol. Liq., 282, 142153.

[5] Yu, B., Li, C.Y., Sun, Y.X., Jia, H.R., Guo, J.Q., and Li, J., 2017, A new azine derivative colorimetric and fluorescent dual-channel probe for cyanide detection, Spectrochim. Acta, Part A, 184, 249-254.

[6] Udhayakumari, D., 2018, Chromogenic and fluorogenic chemosensors for lethal cyanide ion. A comprehensive review of the year 2016, Sens. Actuators, B, 259, 1022-1057.

[7] Tracqui, A., Raul, J.S., Géraut, A., Berthelon, L., and 
Ludes, B., 2002, Determination of blood cyanide by HPLC-MS, J. Anal. Toxicol., 26 (3), 144-148.

[8] Dadfarnia, S., Haji Shabani, A.M., Tamadon, F., and Rezaei, M., 2007, Indirect determination of free cyanide in water and industrial waste water by flow injection-atomic absorption spectrometry, Microchim. Acta, 158 (1), 159-163.

[9] Taheri, A., Noroozifar, M., and Khorasani, M.M., 2009, Investigation of a new electrochemical cyanide sensor based on Ag nanoparticles embedded in a three dimensional solegel, J. Electroanal. Chem., 628 (1-2), 48-54.

[10] Mergu, N., Singh, A.K., and Gupta, V.K., 2015, Highly sensitive and selective colorimetric and offon fluorescent reversible chemosensors for $\mathrm{Al}^{3+}$ based on the rhodamine fluorophore, Sensors, 15 (4), 9097-9111.

[11] Sun, Y., Hu, J.H., Qi, J., and Li, J.B., 2016, A highly selective colorimetric and "turn-on" fluorimetric chemosensor for detecting $\mathrm{CN}^{-}$based on unsymmetrical azine derivatives in aqueous media, Spectrochim. Acta, Part A, 167, 101-105.

[12] Pei, P.X., Hu, J.H., Long, C., and Ni. P.W., 2018, A novel colorimetric and "turn-on" fluorimetric chemosensor for selective recognition of $\mathrm{CN}^{-}$ions based on asymmetric azine derivatives in aqueous media, Spectrochim. Acta, Part A, 198, 182-187.

[13] Hu, J.H., Sun, Y., Qi, J., Li, Q., and Wei, T.B., 2017, A new unsymmetrical azine derivative based on coumarin group as dual-modal sensor for $\mathrm{CN}^{-}$and fluorescent "OFF-ON" for $\mathrm{Zn}^{2+}$, Spectrochim. Acta, Part A, 175, 125-133.

[14] Hidayah, N., Purwono, B., and Pranowo, H.D., 2020, One step synthesis of symmetrical amino azine derivatives using hydrazine hydrate as a reagent, Key Eng. Mater., 840, 257-264.

[15] Kagatikar, S., Sunil, D., Kekuda, D., Kulkarni, S.D., and Abdul Salam, A.A., 2020, New salicylaldehyde azine esters: Structural, aggregation induced fluorescence, electrochemical and theoretical studies, J. Mol. Liq., 318, 114029.

[16] Lee, B., Lee, K.H., Cho, J., Nam, W., and Hur, N.H., 2011, Synthesis of azines in solid state: Reactivity of solid hydrazine with aldehydes and ketones, Org. Lett., 13 (24), 6386-6389.

[17] Safari, J., and Gandomi-Ravandi, S., 2011, Highly efficient practical procedure for the synthesis of azine derivatives under solvent-free conditions, Synth. Commun., 41 (5), 645-651.

[18] Li, W.J., and Han, H.F., 2016, Crystal structure of (E,E)-2',4'-dihydroxyacetophenone azine dimethylformamide disolvate, Acta Crystallogr., Sect. E: Crystallogr. Commun., E72, 467-469.

[19] Mohammadi, A., and Yaghoubi, S., 2017, A new dual colorimetric chemosensor based on quinazolinone for $\mathrm{CN}^{-}, \mathrm{AcO}^{-}$and $\mathrm{Cu}^{2+}$ ions, Sens. Actuators, B, 241, 1069-1075.

[20] Nie, H.M., Gong, C.B., Tang, Q., Ma, X.B., and Chow, C.F., 2014, Visual and reversible detection of cyanide ions in protic solvents by a novel colorimetric receptor, Dyes Pigm., 106, 74-80.

[21] Lin, S.L., Kuo, P.Y., and Yang, D.Y., 2007, Design and synthesis of a coumarin-based acidichromic colorant, Molecules, 12 (7), 1316-1324.

[22] Purwono, B., Anwar, C., and Hanapi, A., 2013, Syntheses of azo-imine derivatives from vanillin as an acid base indicator, Indones. J. Chem., 13 (1), 1-6.

[23] Murugesan, K., Jeyasingh, V., Lakshminarayan, S., Selvapalam, N., Dass, G., and Piramuthu, L., 2021, Anion-binding-induced and reduced fluorescence emission (ABIFE \& ABRFE): A fluorescent chemo sensor for selective turn-on/off detection of cyanide and fluoride, Spectrochim. Acta, Part A, 245, 118943. 